\title{
Novel Stitched Ground Plane Optimizations for Microstrip Patch Antennas at Wi-Fi and WiMAX Applications
}

\author{
Abraham T. Wiri \\ Department of Electrical Engineering, Rivers State University, Port Harcourt, Nigeria \\ Email: wiri.abraham@ust.edu.ng
}

How to cite this paper: Wiri, A.T. (2021) Novel Stitched Ground Plane Optimizations for Microstrip Patch Antennas at Wi-Fi and WiMAX Applications. Open Journal of Antennas and Propagation, 9, 26-43. https://doi.org/10.4236/ojapr.2021.92003

Received: March 19, 2021

Accepted: May 11, 2021

Published: May 14, 2021

Copyright $\odot 2021$ by author(s) and Scientific Research Publishing Inc. This work is licensed under the Creative Commons Attribution International License (CC BY 4.0).

http://creativecommons.org/licenses/by/4.0/

\section{(c) (i) Open Access}

\begin{abstract}
This work explores the optimal mesh structure, stitch density and production technique of stitched ground plane for microstrip patch antenna. Meshed ground plane was used as a generic problem. A stitched ground plane is proposed and designed using Matlab interface to computer embroidery. Using the meshed or stitched ground plane as a case study, the resistance between meshes was analysed and measured. The equivalent resistance between nodes is a function of their distance apart. A finite resistive grid was simulated and compared to measured sets of data. A microstrip patch antenna with stitched ground shows comparable performance to the conventional etched ground of the size in terms of bandwidth. The stitched ground plane has a higher bandwidth than the etched copper ground plane because of the increased thickness of the substrate. Thus, it can be concluded that the use of the interface method shows the possibilities of controlling the stitch density and distances between mesh nodes. The interface increases the stitching density and reduces the electrical resistance between mesh nodes making the antennas flexible and wearable. The functionality of these antenna samples has been tested and validated using microstrip patch ground at $2.45 \mathrm{GHz}$ and $5 \mathrm{GHz}$. Measurement results on the proposed stitched ground planes were compared with the theory of infinite resistive network that shows good agreement.
\end{abstract}

\section{Keywords}

Stitched Ground Plane, Matlab Interface, Method, Meshed Path, Computer-Embroidery

\section{Introduction}

In today's technological advancement, wearable antennas are becoming a major 
part of our daily paraphernalia. Wearable electronics is a fast-growing industry across both civilian and military markets. Textile antennas have been designed to be body-worn while in use for various applications. These textile antennas are used in systems, since they are flexible, for detecting body motion during exercise activity, monitoring heart rate and blood pressure [1]-[6]. The basic requirements for wearable electronics include portability during operation, operation consistency, controllability and robustness that guarantee a good fitness of the electronic to the human body application. Many commercial wearable devices are currently fitness watches and heart rate monitors, but stitched antennas are designed to be integrated into garments. Garment integrated wearables are more challenging due to the unconventional materials used. The stitched antenna consists of a conductive element integrated into a non-conductive material known as the substrate. These stitched antennas are lightweight, flexible, not expensive, easy to produce and can be easily and seamlessly integrated into clothing [7] [8] [9].

Textile structures are used for wearable antennas because they are lightweight, long-lasting, flexible and conformable. This structure is also soft, deformable, breathable, durable, and washable. The main challenges of intelligent clothes are making it flexible and light with electronic functions [2]. Textile antenna has been developed into flexible and light weight to be integrated into clothes. Thess wearable antenna samples can be retrofitted into a garment for application of mobile communication environment where antenna is used in vicinity of human body.

Meshing renders antenna metallization transparent and transparency is evaluated based on the mesh antenna geometry. In the study carried out [10] [11] meshed patch antennas have similar properties to conventional microstrip patch antenna since uses less metal making them optically transparent. In [1] [2] nonuniform meshed patch antennas (NMPAs) were compared to a copper equivalent NMPA and embroidered NMPA, it is concluded that the antennas have high antenna gain with reduced thread usage but meshing causes a decrease in front to back radiation.

A stitch pattern is developed for the proposed antenna using the microstrip patch antenna as the basis for evaluating the performance. Different stitch patterns and densities on the proposed antennas are examined in this work. Solid patch antennas with meshed ground are presented as a reference showing the effects on the resonance frequency. Using these textile substrates makes the antenna light, flexible and relatively inexpensive. For this application Amberstrand 66 is used as the conductive thread [4]. All fabricated textile antennas have been designed to function within the $2.45 \mathrm{GHz}$ industrial, scientific, and medical (ISM) band and $5 \mathrm{GHz}$ wearable wireless local area networks (WLAN) frequencies.

This paper proposes a new stitched ground plane that reduces the usage of the conductive yarn for microstrip patch antenna and resistance between mesh nodes. In Section 2 textile substrate dielectric parameters were characterized by 
using a split post dielectric resonator (SPDR). Stitch optimization for ground plane is done in Section 3. Section 4 presents the design and simulation of microstrip patch antenna and production of the stitched ground plane. The analytical, simulation and measured results of the meshed ground plane are presented in Section 5. In Section 6 it is concluded that the MATLAB interface to computer embroidery could be used to create any meshed geometric pattern for fabric antenna. The stitched ground mesh could equally be replaced with identical resistor for the purpose of verification of approximate theoretical equivalent in infinite grids.

\section{Measurement of Dielectric Substrate}

The fabric materials under test (MUT) were cut according the dimension of cavity that is $13 \mathrm{~cm} \times 13 \mathrm{~cm}$. The thickness of the textile samples was measured. The $Q$ was measured when the resonator was empty, then the MUT was placed in the resonator and measured. The $\mathrm{Q}$ factor of the empty cavity, the thickness of sample and MUT inside the cavity was fed to the computer program. The measurement setup of split post dielectric resonator (SPDR) [12] was used to extract permittivity and loss tangent of felt and denim sample that is used for embroidery of textile antennas in this study. See Figure 1. The dielectric measurement result of the single layer denim is thickness $0.85 \mathrm{~mm} \quad \varepsilon_{r}=1.97 \tan \delta=0.07$. For a felt fabric of $1 \mathrm{~mm}, \varepsilon_{r}=1.2$ and $\tan \delta=0.0013$ measured. The Q meter measures the $S_{21}$ results using split post dielectric resonator without a vector network analyzer. The $\mathrm{Q}$ factor was measured at $-3 \mathrm{~dB}$ bandwidth of $\mathrm{S}_{21} \mathrm{using} \mathrm{Q}$ meter and computed using.

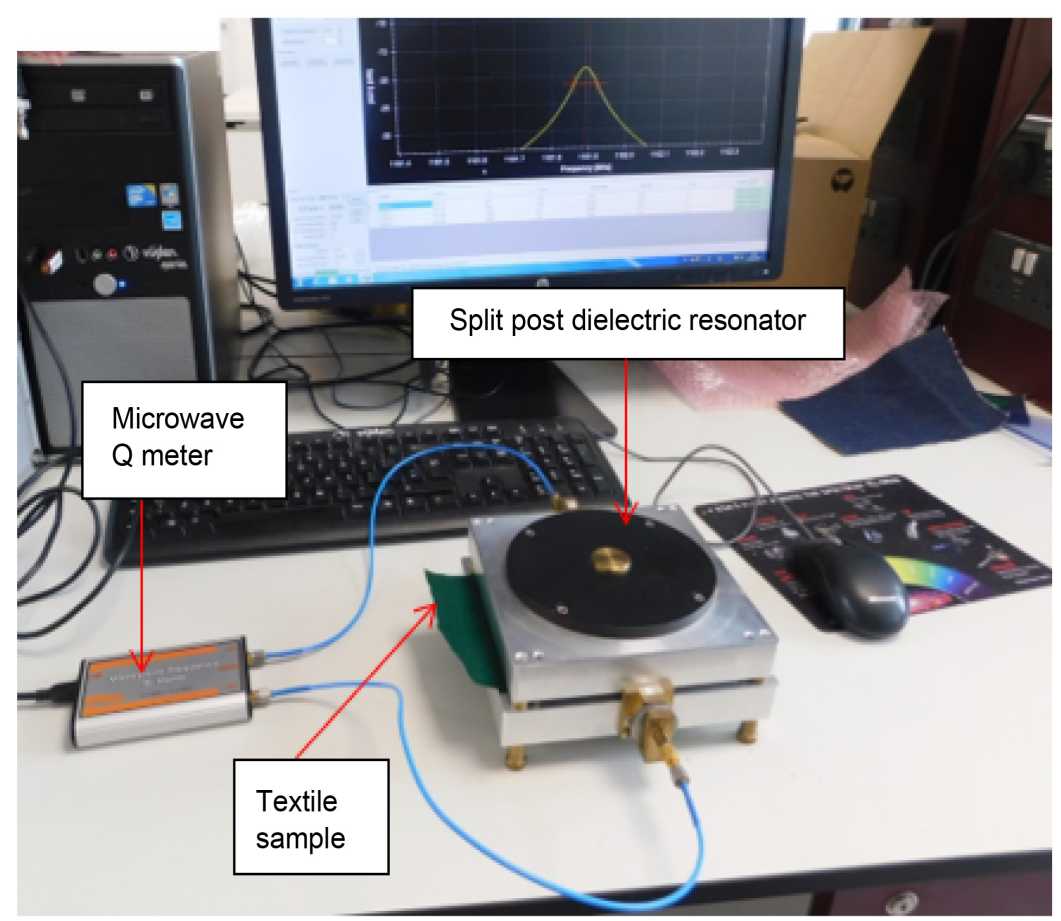

Figure 1. Measurement setup for dielectric parameters of textile samples. 


$$
Q=\frac{f_{r}}{f_{h_{3 \mathrm{~dB}}}-f_{l_{\mathrm{dBB}}}}
$$

where $f_{r}$ is the resonant frequency while $f_{h_{3 \mathrm{~dB}}}-f_{l_{3 \mathrm{~dB}}}$ is $-3 \mathrm{~dB}$ bandwidth.

From the measurement, it is observed that the two fabric samples have low permittivity. Fabric samples are porous in structure.

\section{Stitch Pattern Optimization}

The study of different stitch pattern and sewing type for meshed patch antennas results in different effects on embroidery accuracy and RF performances. Embroidery designs use several sewing types such as zigzag stitch, fill stitch, and spiral stitch. The automated embroidery machines in Loughborough University is used to transform the antenna designs into a stitching pattern for all the stitched antennas [3]. Three different stitching types were created and generated using MATLAB as indicated in Figure 2. When manufacturing a meshed conductive surface, the embroidery machine is, ideally to traverse each branch of the mesh only once. This gives gains in terms of production time as well as economy of yarn use. Figure 2 shows three possible mesh patterns, two of which meet the criterion of stitching each path only once. The mathematical solution to the problem is not trivial, requiring the evaluation of the Euler path. The patterns were created using a set of coordinates geometry and linear equation to actualize the patterns. Stitches are formed by interlocking an upper and a lower yarn (looper).

The stitch pattern for the antennas were created using MATLAB. The MATLAB code is written to reproduce the required stitch pattern proposed. Personal embroidery machine (PE-NEXT) file format is in a -pes file and the instructions for creating pattern commands are "end", "stop", "jump" and "trim". The embroider Modder 2.00 software allows one to edit, scale and convert embroidery files to other formats using the libembroidery library. This library supports writing and reading. CSV (comma separated values) format files. The file format can

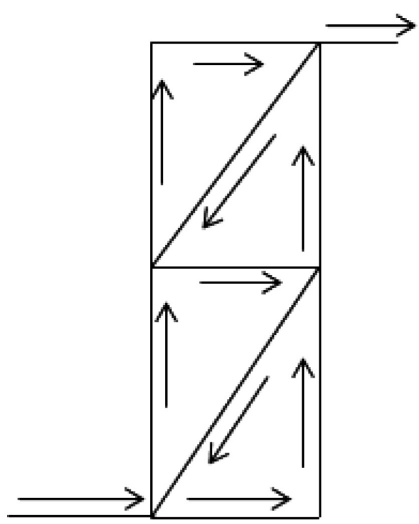

(a)

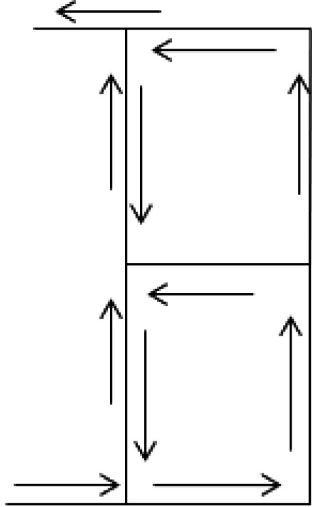

(b)

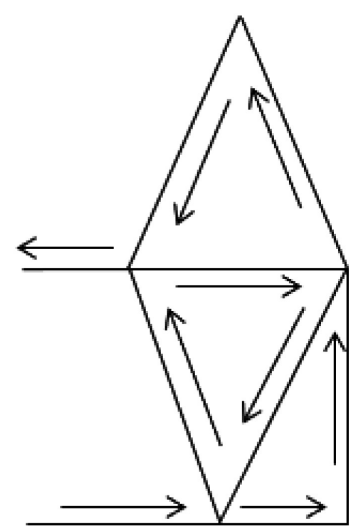

(c)

Figure 2. Three representative stitch patterns: (a) single stitched; (b) same path double stitched; (c) Path single stitched. 
be viewed in Microsoft excel or Notepad since it is in a spreadsheet. The process conversion from comma separated valves (CSV) to embroidery file format (.PES) that contains embroidery instructions is shown in Figure 3. Once the conversion is successful, the pattern is viewed in the embroidery software to check how the pattern looks. The designed pattern is exported to the embroidery machine via a USB port.

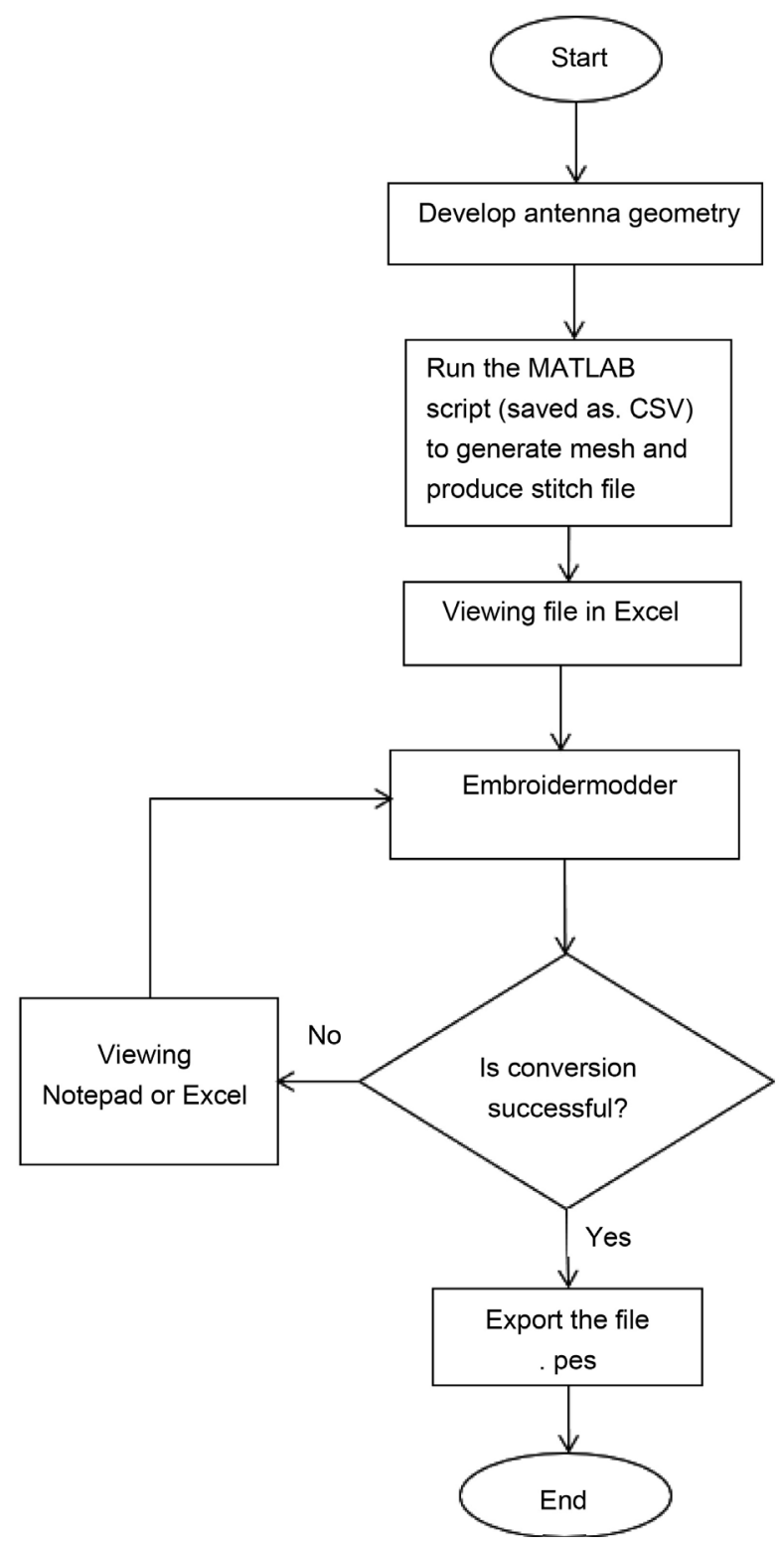

Figure 3. MATLAB interface to computer embroidery techniques used for stitch pattern formation.

\section{Antenna Description}

The majority of the studied carried out onfabricantennas in the literature is centred around microstrip patch antennas as a result of its advantages of miniaturisation, low profile, compactness, ease of integration in clothing materials and 
good radiation patterns. Fabric antennas consist of upper and lower conductive layers of antenna patchs and ground plane and a middle layer of dielectric substrate [1] [2] [3] [4]. A planar structure is a basic requirement for wearable textile antenna. A microstrip line-fed rectangular (square) patch as shown in Figure 4 was designed using the transmission line model considering the dielectric constant $\left(\varepsilon_{r}\right)$, resonant frequency $\left(f_{r}\right)$ and height of substrate $\left(h_{s}\right)$ for calculating the physical dimensions of the patch using Equations (2)-(10) [13]. The dielectric constant is of a lower value to enhance fringing and radiation. The bandwidth of the patch is a function of substrate height. Patch antenna dimension is $W_{p}$ in $\mathrm{mm}$ and $L_{p}$ in $\mathrm{mm}$ where $\lambda$ is the free space wavelength at $2.45 \mathrm{GHz}$ and $5 \mathrm{GHz}$ wireless networking bands. The dimensions of the feed line are $L_{f} \times W_{f}$ and feed line inset $\left(y_{0}\right)$ for impedance matching. The dimension of substrate and ground plane is given as $\left(W_{s} \times L_{s}\right.$ and $\left.h_{s}\right)$ and $\left(W_{g} \times L_{g}\right.$ and $\left.t_{g s}\right)$ all in mm respectively. The microstrip patch antenna has been designed for two applications.

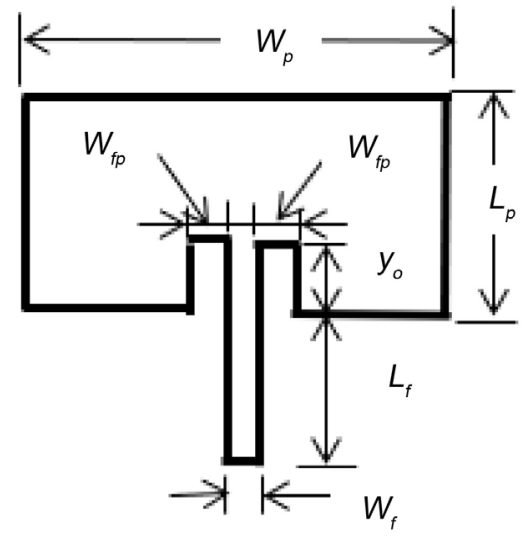

(a)

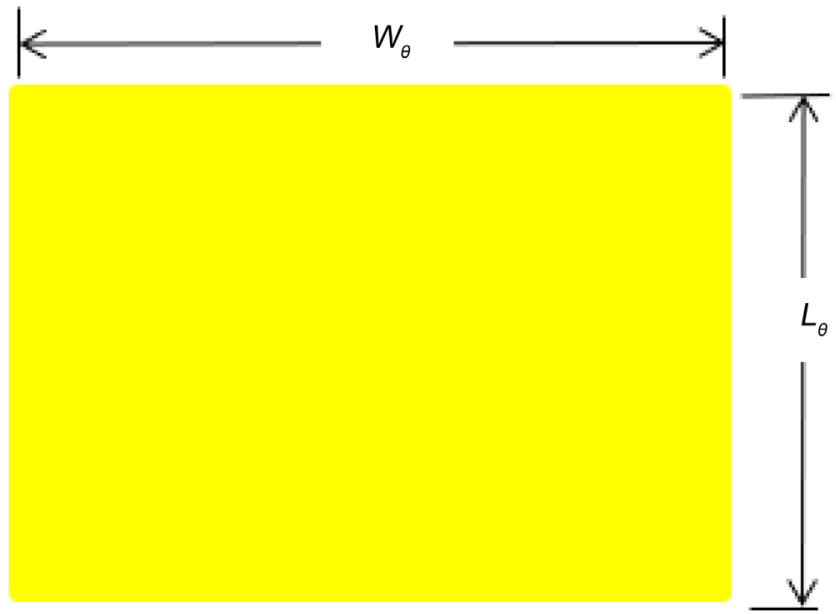

(b)

Figure 4. Geometry of proposed inset microstrip fed patch antenna: (a) Top conductor and; (b) Solid ground. 
The embroidery technique is used to place a conductive yarn onto Denim or Felt substrate for the ground plane of patch antennas operating at $2.45 \mathrm{GHz}$ and $5 \mathrm{GHz}$ frequencies. The substrate dielectric constant and loss tangent are determined by measurement using split post dielectric resonators (SPDR) for the fabric samples. The patch antenna is constructed on a two layer substrate having a FR4 of relative permittivity $\varepsilon_{r}$ of 4.3 loss tangent $(\tan \delta)$ of 0.018 and relative permittivity of Denim fabric of $0.7 \mathrm{~mm}, \varepsilon_{r}$ of 1.97 and loss tangent $(\tan \delta)$ of 0.0707 and and for a felt fabric of $1 \mathrm{~mm}, \varepsilon_{r}$ of 1.2 and $(\tan \delta)$ of 0.0013 . A copper layer of thickness of $0.035 \mathrm{~mm}$ was used on the reference antenna.

Two types of conductive thread materials were used for the fabrication of the prototype stitched antennas: Liberator-20 and Amberstrand 66 (metal clad polymer). Liberator- 20 consists of a yarn of 20 strands of diameter $0.22 \mathrm{~mm}$. Each strands has a Vectran fiber core with silver coating. The DC resistance of Liberator-20 is $2 \Omega / \mathrm{ft}$ which gives an effective conductivity of $4.5 \times 10^{7} \mathrm{~S} / \mathrm{m}$. Liberator-20 is created by Syscom Advanced Materials [2].

The following formulae for the antenna design are taken from Balanis [13]:

Effective dielectric constant

$$
\begin{gathered}
\varepsilon_{\text {reff }}=\frac{\varepsilon_{r}+1}{2}+\frac{\varepsilon_{r}-1}{2}\left[1+12 \frac{h}{W}\right]^{-1 / 2} \\
\varepsilon_{\text {reff }}\left(\frac{W}{h} \gg 1\right)
\end{gathered}
$$

Effective length

$$
L_{\text {eff }}=L+2 \Delta L
$$

Normised extension length

$$
\frac{\Delta L}{h}=0.412 \frac{\left(\varepsilon_{\text {reff }}+0.3\right)\left\lceil\frac{W}{h}+0.264\right\rceil}{\left(\varepsilon_{\text {reff }}-0.258\right)\left[\frac{W}{h}+0.8\right\rceil}
$$

Resonant frequency

$$
\left(f_{r}\right)_{010}=\frac{1}{2 L \sqrt{\varepsilon_{r}} \sqrt{\varepsilon_{r} \mu_{0}}}
$$

There are various way of feeding the microstrip patch antenna which include coaxial probe feed, microstrip line, inset fed, aperture coupling and proximity coupling. Most designs of microstrip antenna are fed by simple coaxial probe because of ease of fabrication. In this study the rectangular microstrip patch antennas are fed by a microstrip line with inset feed. The inset feed is used for microstrip patch antenna to improve the impedance match with planar feed configuration. The input impedance of microstrip patch antenna depends on the feed position for probe feed or the microstrip feed inset [14]. The transmission-line model represent the patch as a low-impedance line whereby the width of the patch determines the impedance and the effective dielectric constant. A microstrip 
patch consists of parallel plate radiation conductance and capacitive susceptance that loads both the radiating edges of the patch Balanis [13] gives the radiation conductance for a parallel-plate radiator as

$$
\begin{gathered}
G=\frac{\pi W}{\eta \lambda_{0}}\left[1-\frac{(k H)^{2}}{24}\right] \\
R_{e}=\frac{1}{2 G}
\end{gathered}
$$

The computed value of $G$ was $2.49 \mathrm{~m} \Omega$ and $R_{e}$ the input resistance at the edge, is $200 \Omega$ with $y_{0}$ inset distance. The capacitive susceptance in relation to the effective strip extension is given as

$$
B=0.01668 \frac{\Delta}{H} \frac{W}{\lambda} \varepsilon_{\text {eff }}
$$

Microstrip antenna is fed from the edge using an inset line where the gap on either side ofstrip line is equal to its width. The feed location $y_{0}$ was computed from Equations (5)-(9) using a radian angle measure.

$$
\begin{gathered}
R_{i}=R_{e} \sin ^{4} \frac{\pi y_{0}}{L}, 0 \leq y_{0} \leq \frac{L}{2} \\
y_{0}=\frac{L}{\pi} \sin ^{-1}\left(\frac{R_{i}}{R_{e}}\right)^{1 / 4}
\end{gathered}
$$

Computed values of $50 \Omega$ feed inset, $y_{0}$ for $5 \mathrm{GHz}$ was $3.5 \mathrm{~mm}$ and for 2.45 $\mathrm{GHz}$ the value is given as $7.5 \mathrm{~mm}$. The values were compared to the computed values in [13].

\section{Production of Textile Meshed Ground Plane}

A digital embroidery machine at the Loughborough University model Brother Pro PR1000e Entrepreneur was used to realize the fabrication of the stitched ground plane for the Microstrip patch antennas. The thread used for this study was a Multi-thread conductive yarn Amberstrand Silver 66. One single thread of Amberstrand is made of 66 identical filaments. The diameter of the Amberstrand filament is approximately $17 \mu \mathrm{m}$ [1] [2]. The stitching was performed along the horizontal step and vertical step directions for antennas PA2, PA3, PA4 and PA5. The lock stitch method was used where two threads: conductive thread and non-conductive thread for stitched formation. A stitch density of 4.5 lines/mm was used stitching of the ground plane. Current prefers to follow the stitch direction rather jump from one yarn to another [4]. The number of stitches for ground plane for antenna PA3 and PA4 was 449. The number of stitches for antenna sample PA2 is 313 and PA5 is 1161 . Stitching the ground plane on to fabric material (felt or denim) first, the stitched ground plane is cut and attached the stitched ground plane to the FR4 substrate using repositionable adhesive.

The patch antennas samples were designed of top (solid patch), ground plane 
conductive mesh and at the middle a dielectric substrate. Amberstrand was stitch into nonconductive substrate (example felt and denim) to create conductive mesh with equal mesh density in both orthogonal directions of the ground plane using the process of embroidery. The stitching concept employed the principle of lock stitch pattern. Stitched antennas always result in an anisotropic pattern where the conductivity of the textile depends on the direction of the current flow in the pattern, pattern geometry and the stitching density of the design [4].

Antennas are named as follows, Antenna PA1 solid patch on solid ground plane, antenna PA2 solid patch etched on FR4 and conductive thread is stitched on felt material, antenna PA3 solid patch and meshed ground (using conductive thread on felt material), antenna PA4 solid patch on FR4 substrate and conductive thread stitched on denim fabric, antenna PA5 solid patch on FR4 substrate behind is a felt fabric material stitched triangular meshed formation, antenna MGP1 meshed patch on mesh ground plane $(2 \mathrm{~mm} \times 2 \mathrm{~mm})$ and antenna MGP3 solid patch on FR4 meshed ground similar (to PA2), antenna MGP2 meshed patch on solid ground, antenna and antenna MGP4 solid patch on meshed ground $(2 \mathrm{~mm} \times 2 \mathrm{~mm})$.

\section{Results}

The reflection coefficients of the patch antenna with stitched ground plane were measured using a 37397D network analyser. The structure and dimension of the proposed microstrip patch antenna is shown above. The ground plane covers the entire side of the substrate and is made of copper sheet of $0.035 \mathrm{~mm}$ thickness. The radiating element is designed with the same thickness copper. The substrate is FR4 ( $\varepsilon_{r}=4.3$ and loss tangent $\left.\delta=0.018\right)$ has a size of $W_{g} \times L_{g}=70 \mathrm{~mm} \times 65 \mathrm{~mm}$, substrate height $h_{s}=1.6 \mathrm{~mm}$ is used for all the antennas. The size of the patch $W_{p} \times L_{p}=38 \mathrm{~mm} \times 28 \mathrm{~mm}$. The feedline has a characteristic impedance of $50 \Omega$ for maximum power transfer. The simulated and measured reflection coefficient are shown in Figure 5. The reflection coefficient is at centre frequency of the Wi-Fi band $(2.4-2.485 \mathrm{GHz})$. Measured $\mathrm{S}_{11}$ is $-21.48 \mathrm{~dB}$ at $2.43 \mathrm{GHz},-10 \mathrm{~dB}$ Bandwidth $49 \mathrm{MHz}$ and simulation $\mathrm{S}_{11}$ is -25.81 $\mathrm{dB}$ at $2.46 \mathrm{GHz}-10 \mathrm{~dB}$ bandwidth $87 \mathrm{MHz}$.

The reflection coefficient $\left(S_{11}\right)$ of a solid patch antenna (PA1) with a copper ground plane sample is shown in Figure 6. PA1 simulation $\mathrm{S}_{11}$ result is $-21.4 \mathrm{~dB}$ at $4.97 \mathrm{GHz},-10 \mathrm{~dB}$ bandwidth of $200 \mathrm{MHz}$ and measured $\mathrm{S}_{11}$ is $-25.6 \mathrm{~dB}$ at 4.92 $\mathrm{GHz},-10 \mathrm{~dB}$ bandwidth $200 \mathrm{MHz}$. This sample (PA1) was used as a case study. Several antenna samples were designed and fabricated using different substrates such as denim and felt. Measurement results and simulation of the various stitched patch ground at $5 \mathrm{GHz}$ were compared to the solid patch antenna.

The measurements were carried using the point (0.0) indicated on Figure 7 as the referenced node. Analogue meter (HP4328A milliohm meter) was used but had its precision augmented by connecting a high impedance digital meter in 
parallel with the moving coil panel meter in the instrument. The digital meter was calibrated however due to the normalisation this effect was cancelled out. The theoretical value for Amberstrand(R) $=2 \Omega /$ foot $=6.54 \Omega \mathrm{m}^{-1}$. For example the distance between two nodes of $7 \mathrm{~mm}=46.04 \mathrm{~m} \Omega$. This value is an approximation because across the meshes the distances look equal. Pressing down the probe of the multimeter gives a better result when measuring between nodes across a meshed-on fabric material.

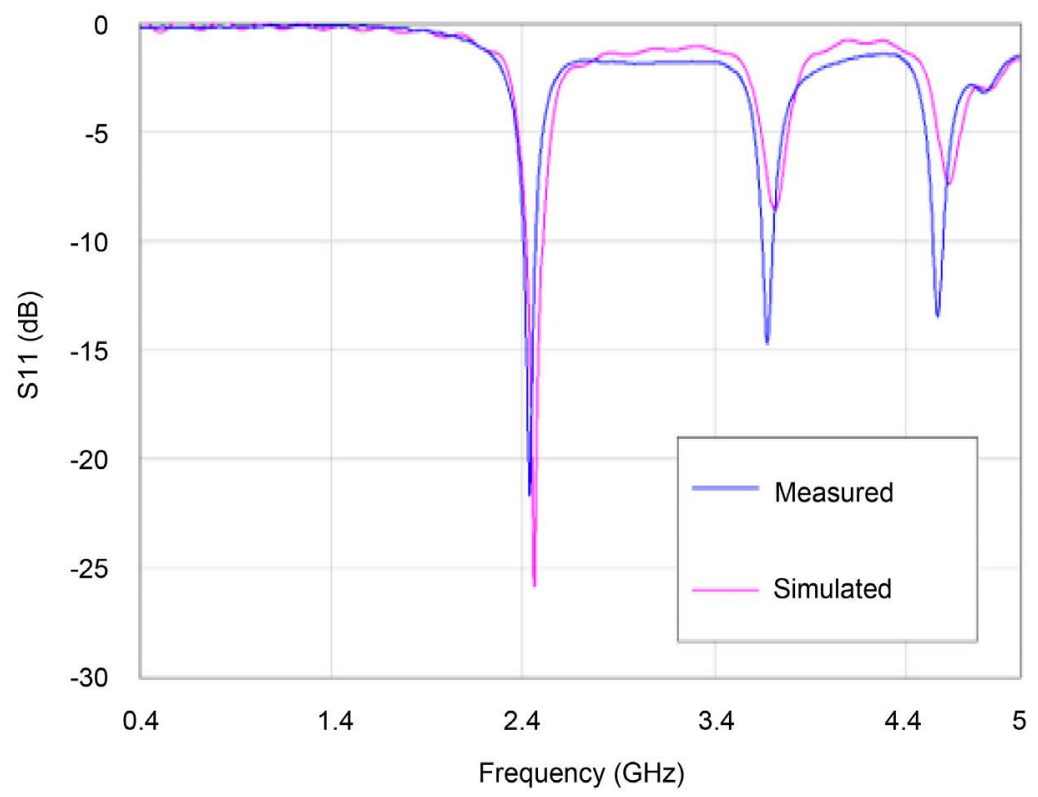

Figure 5. Comparison between simulation and measurement of the proposed microstrip patch (inset feed) at $2.45 \mathrm{GHz}$.

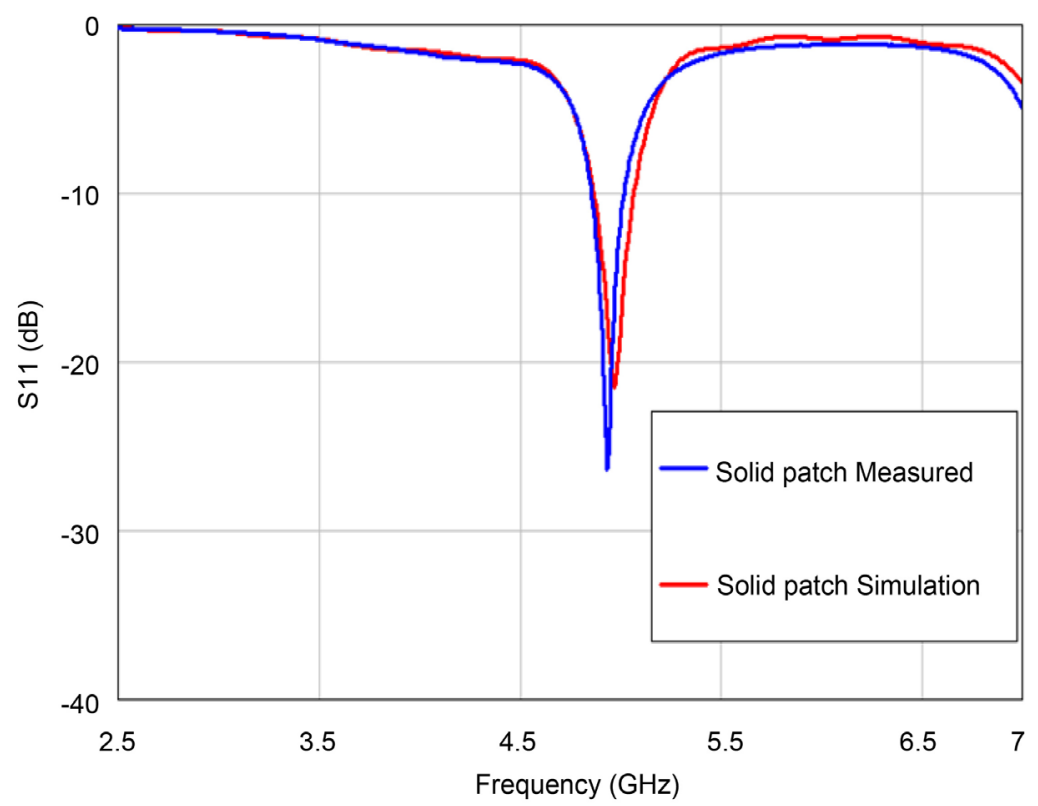

Figure 6. Simulated and measured $S_{11}$ curves of the antenna PA1 (solid ground planes) at $5 \mathrm{GHz}$. 


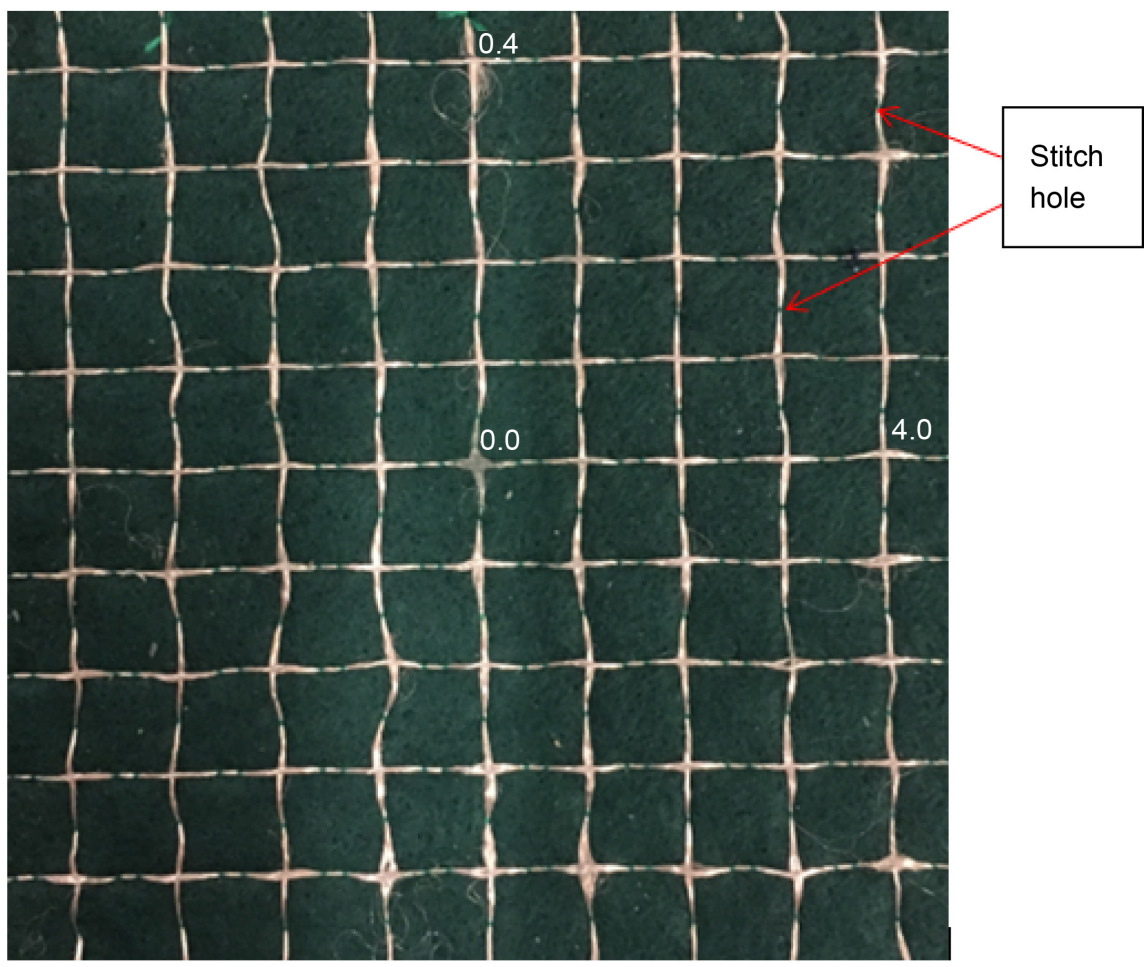

Figure 7. Measurement referenced point of meshed ground plane.

The analytical, simulation and measured result of the meshed ground plane are shown in Figure 8. The data are simulation, analytical and measurement results [15]. The meshed grid is simulated with a uniform conductor while the fabrication or embroidery is carried out with a non-uniform conductor. The meshed grid point in the measurement across the points varies due to expansion of Amber strand conductors. The difference in the results is a result of the distances between meshed and the uniformity of the conductors across the grid. The separation between two nodes is not equal because of manufacturing tolerance. The meshed ground plane of the size $8 \times 8$ using an offset distance of $1 / 2$ grid was designed using the proposed stitching pattern. The first stitch patterns created were not connecting properly at all node points when measured but to improved connections between the vertical and horizontal sections, an offset grid was generated. The simulation considering 7 points gives: $0.9869,1.0002,1.0606$, $1.0871,1.0361,1.0871,1.5638$ and the measurement gives a 1.0968, 1.175, 1.3466, $1.427,1.1316,1.3119,1.1487$. The average error across the grid nodes $(8 \times 8)$ is about $23.51 \%$. Note the edge effect on the measurements, which are on smaller array than the modelled mesh. Once the mesh is larger the measured result the resistances across the mesh will be similar to the infinite meshed network. They mesh that was simulated and stitched samples on felt and denim substrate was (8 $\times 8$ ) which is small but using a larger mesh edge effects will be reduced. From the results some errors in the values of resistance are seen across the edges [16] [17].

Two types of feed were considered in the modelling of the microstrip patch 


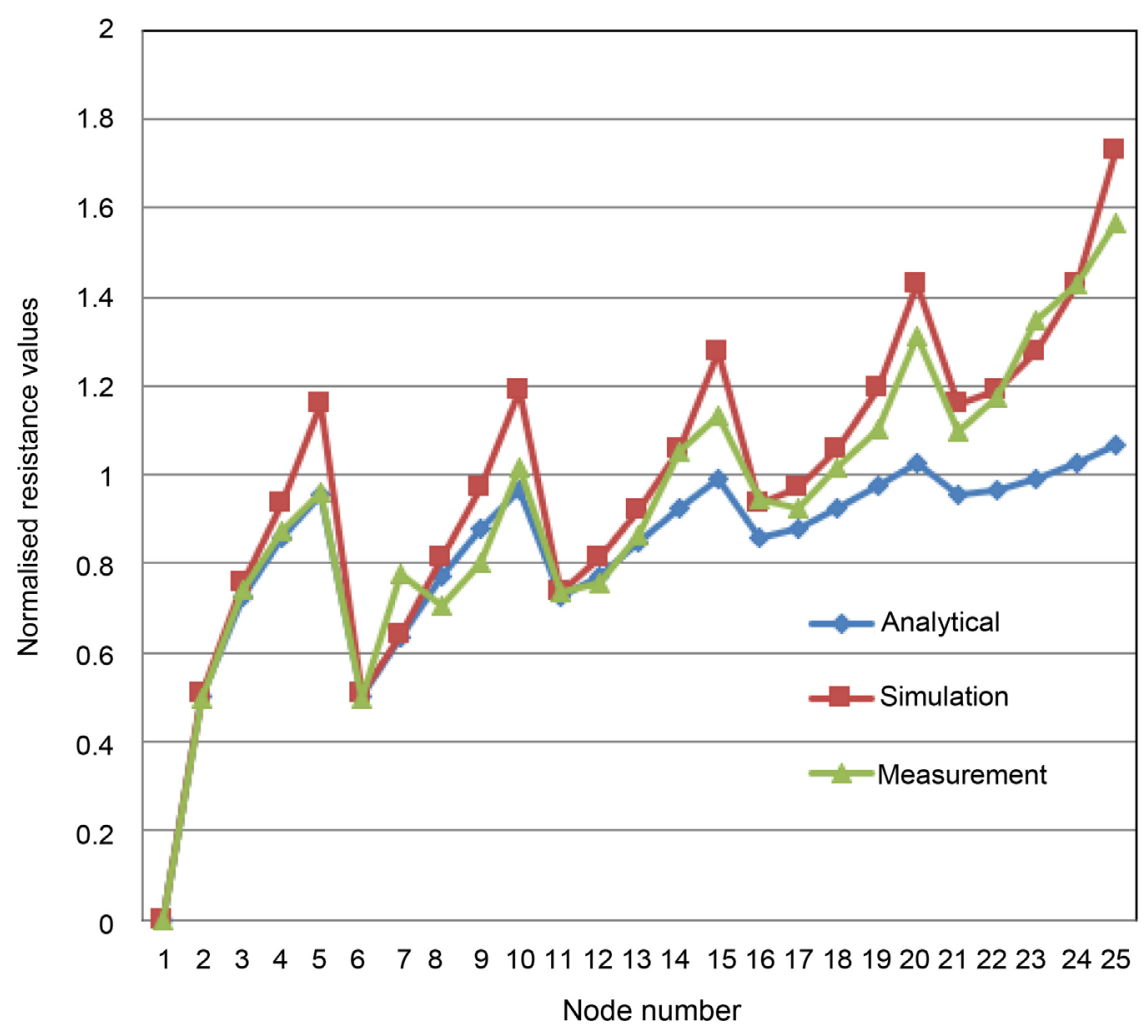

Figure 8. Comparison of measured point with simulation and analytical results of stitched ground plane.

antenna. The inset feed gives a better match and higher resonant frequencies than the direct feed microstrip line because the input impedance is clearly defined. The inset fed microstrip antenna has an efficiency of $91 \%$ while the microstrip line fed has an efficiency of $88 \%$ at the center operating frequency of $2.45 \mathrm{GHz}$ [3]. From the results at $-10 \mathrm{~dB}$ bandwidth for microstrip patch at 5 $\mathrm{GHz}$, a bandwidth of $150 \mathrm{MHz}$ was realized (see Figure 6) but the value of 861 $\mathrm{MHz}$ bandwidth was achieved using the triangular stitched ground plane pattern. The rectangular stitched pattern used for the same microstrip patch antenna give a $-10 \mathrm{~dB}$ bandwidth of $780 \mathrm{MHz}$. These results of the meshed stitched antennas show a bandwidth broadening when the antenna is stitched on fabrics. Meshed version of the antenna will be advantageous if applied because less materials is required, implying less weight and cost, they can equally be integrated into clothing for wearable applications.

The stitched antenna was placed on a rigid substrate of FR4 and compared with etched antenna PA1 as in Figure 9. All the stitched pattern was fastened on the FR4 substrate and the stitching were done $2 \mathrm{~mm}$ spacing based on the dimension of the Amberstrand. Amberstrand Silver 66 thread was used to actualize the design. This antenna consists of three layers: the top patch, the dielectric substrate (FR4) and a thin fabric material on which the stitching of the ground plane. The same dimension of the ground plane $(44 \mathrm{~mm} \times 48 \mathrm{~mm})$ was used for the stitching the designs. Antenna PA3 is on a felt fabric ground plane with total 
thickness of the substrate (approximately $2.6 \mathrm{~mm}$ ). Antenna sample PA4 is placed on denim fabric.

The simulated and measured $S_{11}$ of three samples of stitched antenna is depicted in Figure 10. Measured $\mathrm{S}_{11}$ of PA3 $-25.8 \mathrm{~dB}$ at $5.31 \mathrm{GHz} 800 \mathrm{MHz}-10 \mathrm{~dB}$ bandwidth, Simulated $\mathrm{S}_{11}$ of PA3: $-32.7 \mathrm{~dB}$ at $4.56 \mathrm{GHz} 500 \mathrm{MHz}-10 \mathrm{~dB}$ bandwidth. The differences between the simulation and measurement due to inaccuracy of thickness of the rigid substrate and fabrication errors. Measured $\mathrm{S}_{11}$ result of PA3: $-30.7 \mathrm{~dB}$ at $5.31 \mathrm{GHz} 680 \mathrm{MHz}-10 \mathrm{~dB}$ bandwidth while the simulated $\mathrm{S}_{11}$ result $-25.2 \mathrm{~dB}$ at $5.46 \mathrm{GHz} 420 \mathrm{MHz}-10 \mathrm{~dB}$ bandwidth, the simulation and measurement agreed for the antenna sample PA4. However, PA3 has higher impedance bandwidth than PA4 as a result of the substrate thickness. The antenna sample PA4 has a center frequency of -30.7 at $5.31 \mathrm{GHz}$ compared with PA3 $-25.8 \mathrm{~dB}$ at $5.46 \mathrm{GHz}$. Antenna sample PA5 stitched on a denim substrate in triangular geometry have $-10 \mathrm{~dB}$ bandwidth of $861 \mathrm{MHz}$ at $-15.2 \mathrm{~dB}$. The difference between the measurement and simulated results may be attributed to two reason, air gap between the FR- 4 and fabric layer which was not considered during simulation. The adhesive spray used for fixing the fabric to FR-4 was not taken into consideration during simulation.

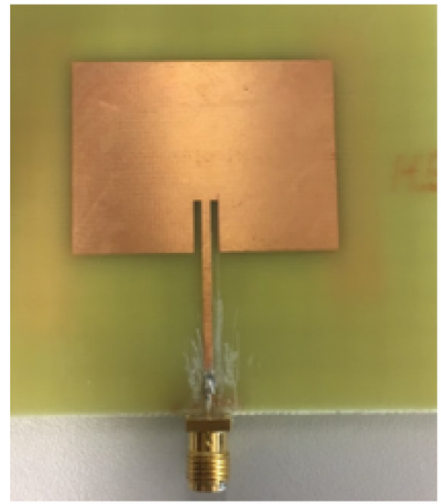

(b)

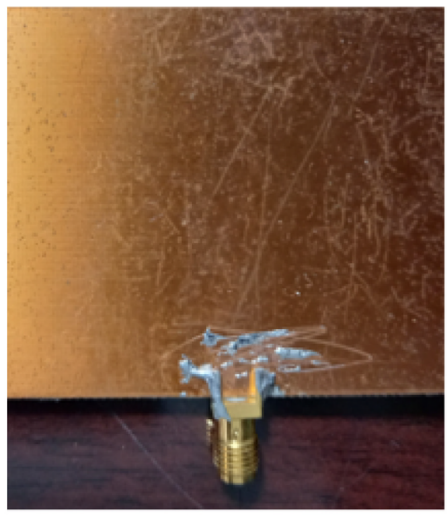

(a)

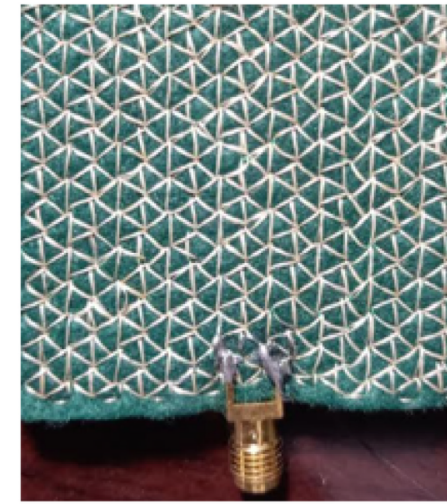

(d)

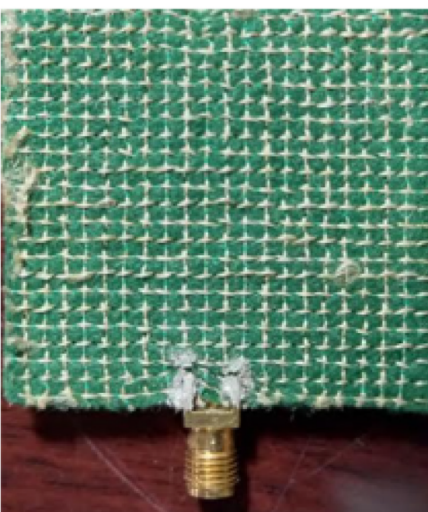

(c)

Figure 9. Representative examples of solid and stitched ground planes for microstrip antennas (a) solid ground plane (PA1), (b) top patch, (c) rectangular ground plane and (d) triangular stitched ground plane. 


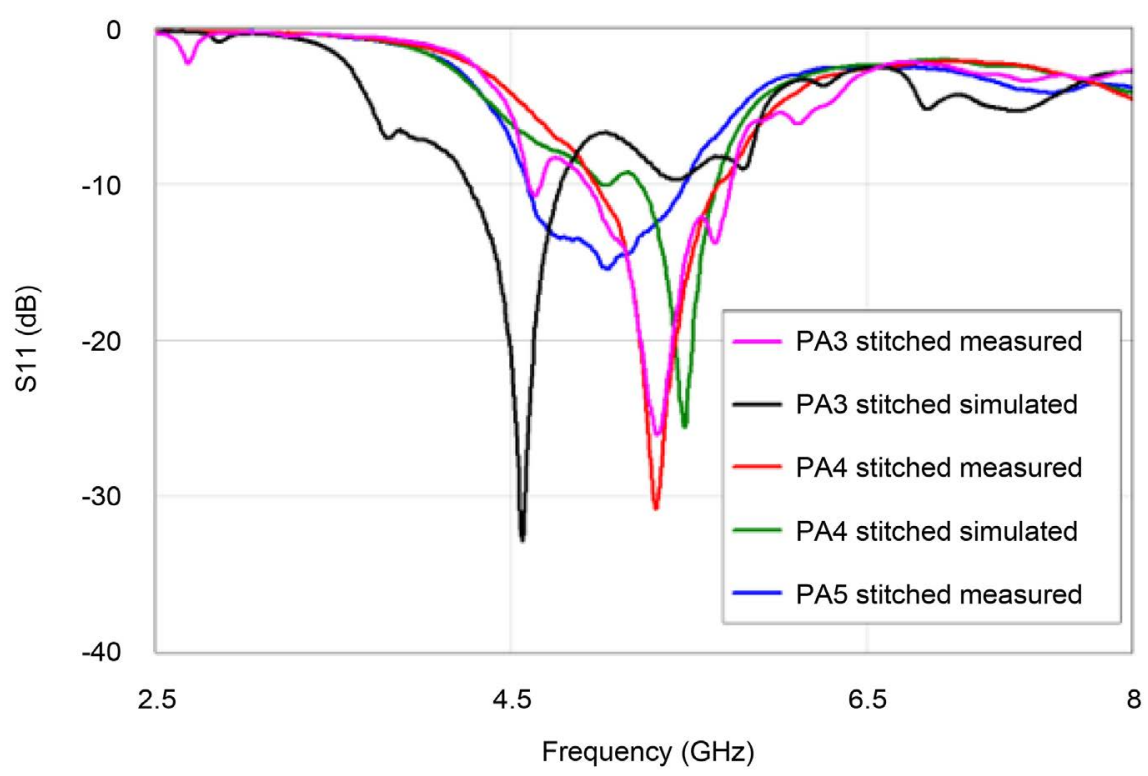

Figure 10. Measured $S_{11}$ results of antennas with different stitched ground plane on different textile substrate.

Antenna PA3 was measured for the reflection coefficient $\left(S_{11}\right)$ when placed on body as shown in Figure 11. The measured were carried out considering a gap of $3 \mathrm{~mm}$ between the body and antenna. The $S_{11}$ off-body measurement is 5.18 $\mathrm{GHz}$ at $-23.78 \mathrm{~dB}$ with $-10 \mathrm{~dB}$ bandwidth of $0.651 \mathrm{GHz}$ while on body measurement $4.781 \mathrm{GHz}$ at $-15.26 \mathrm{~dB}$ and $5.316 \mathrm{GHz}$ at $-23.55 \mathrm{~dB}$, with $-10 \mathrm{~dB}$ bandwidth of $0.86 \mathrm{GHz}$. The $-10 \mathrm{~dB}$ bandwidths in free space and worn does not change significantly. The on-body measurement shows a bandwidth broaden and no change in resonant frequency except in two modes.

Antenna sample PA1 is a solid patch with solid ground plane and antenna sample MGP1 a meshed patch with meshed ground plane both same dimensions. They are fabricated on FR-4 substrate of $1.6 \mathrm{~mm}$ thickness. PA1 simulation $\mathrm{S}_{11}$ result is $-21.4 \mathrm{~dB}$ at $4.97 \mathrm{GHz},-10 \mathrm{~dB}$ bandwidth $200 \mathrm{MHz}$ and measured $\mathrm{S}_{11}-25.6 \mathrm{~dB}$ at $4.92 \mathrm{GHz},-10 \mathrm{~dB}$ bandwidth $200 \mathrm{MHz}$ while MGP1 measured $\mathrm{S}_{11}-24.2 \mathrm{~dB}$ at $4.70 \mathrm{GHz},-10 \mathrm{~dB}$ bandwidth $220 \mathrm{MHz}$ and simulation at $-26.9 \mathrm{~dB}$ at $4.82 \mathrm{GHz}, 240 \mathrm{MHz}$. The drop in frequency of meshed patch with meshed ground (MGP1) is lower by $4.47 \%$ as compared to PA1 of the same dimensions but higher impedance bandwidth. The discrepancies between the measured and simulation as a result errors of substrate permittivity [3]. The radiation pattern was stimulated at $4.82 \mathrm{GHz}$ as shown in Figure 12 where the E-plane and H-plane shown that leakages on the meshed ground plane. The pattern of the meshed patch antenna does not change as compared with the solid patch result. Meshing the ground plane of the patch does not change the radiation pattern. The solid patch has a directivity of $7.03 \mathrm{dBi}$ and the directivity of the meshed patch is 6.91 $\mathrm{dBi}$. Both directivities show only a small change when antenna is meshed. The maximum directivity of the patch antenna (PA1) to the directivity at the real is given as $\mathrm{FBR}_{\mathrm{dB}}=18.32 \mathrm{~dB}$. For antenna MGP1 has a $\mathrm{FBR}_{\mathrm{dB}}=10.63 \mathrm{~dB}$ which 


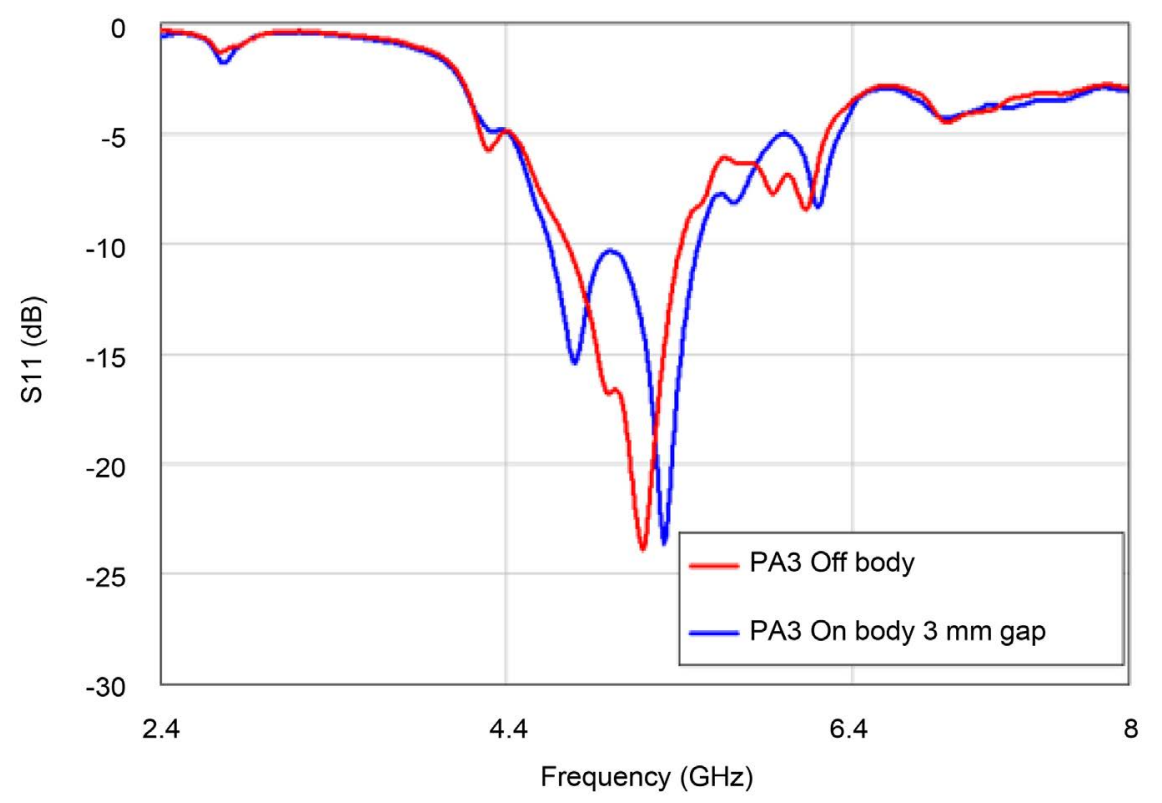

Figure 11. Measured $S_{11}$ of antenna sample PA3 off and on body.
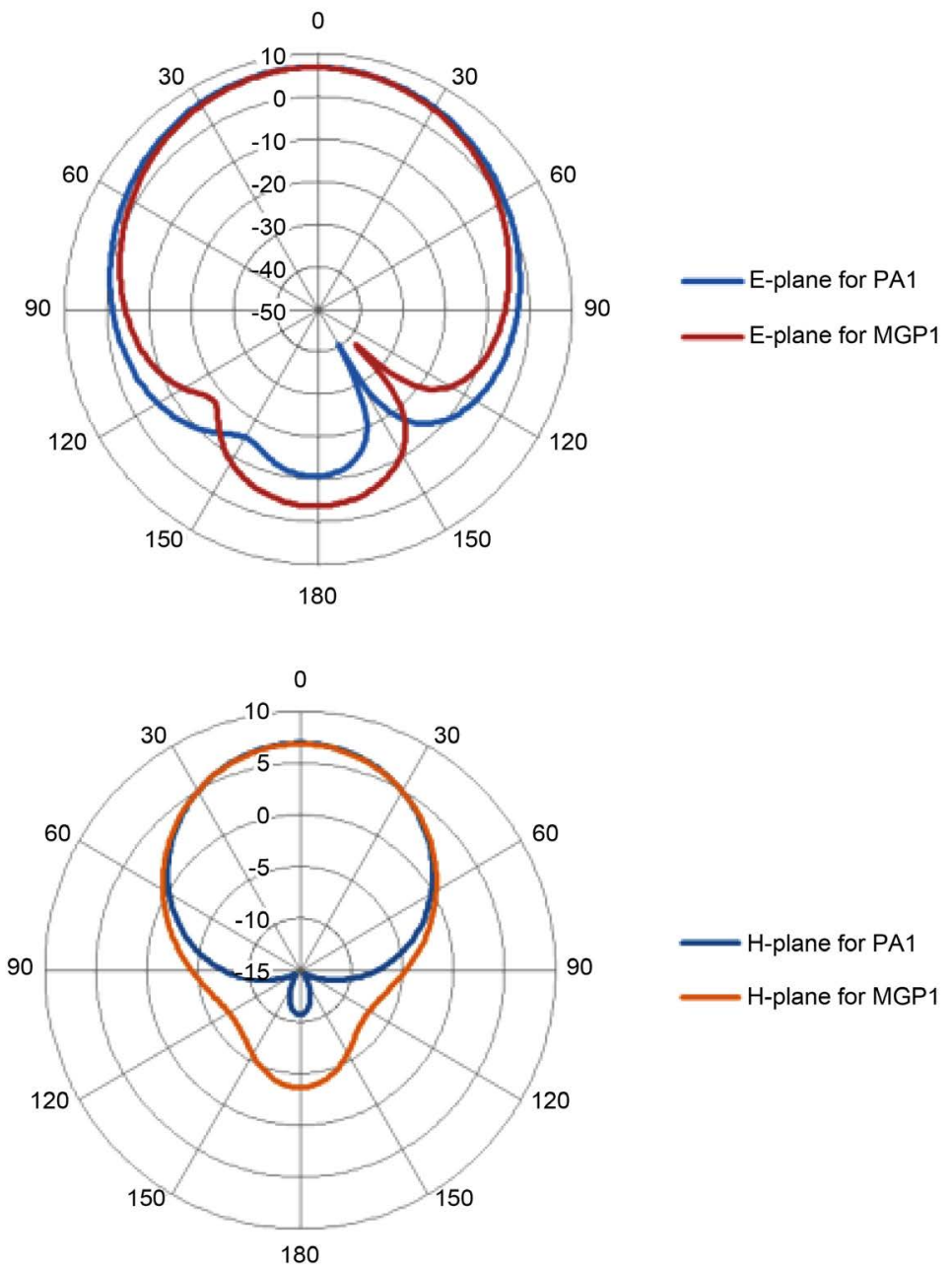

Figure 12. Stimulated radiation pattern of antenna samples MGP1 and PA1. 
shows leakage as a result of meshing the patch antenna and the ground plane. The conventional microstrip patch antenna (PA1) and the microstrip patch with meshed ground in H-plane and E-plane at resonant frequencies are demonstrated in Figure 12. Meshing the ground plane does not change the shape of the pattern for the patch antenna but only causes some back radiation where leakage on the ground plane. The patterns are normalized to the peak gain at each frequency.

\section{Conclusions}

The MATLAB interface to the computer embroidery method is used to control the stitching techniques and stitching density of embroidery machine designs. Three sets of geometric patterns were created include rectangular, square and triangular mesh. These patterns were stitched onto denim and felt fabric materials to provide a microstrip patch ground plane. The rectangular and square patterns use less yarn compared to the triangular patterns. However, the method can be used to create any geometric pattern desired for any antenna ground plane. The solid ground plane of the microstrip antenna was replaced with a stitched ground plane for applications at $2.45 \mathrm{GHz}$ and $5 \mathrm{GHz}$. This method has proven successful based on results from the ground plane designs carried out in this study. Measurement results on the proposed stitched ground planes were compared with the theory of infinite resistive network that shows good agreement.

The meshed ground plane of the size $8 \times 8$ using an offset distance of $1 / 2$ grid was designed using the proposed stitching pattern. The first stitch patterns created were not connecting properly at all node points when measured but to improved connections between the vertical and horizontal sections, an offset grid was generated. Measurement results on the proposed stitched ground planes were compared with the theory of infinite resistive network that shows good agreement.

The method employed in this study shows the possibilities of compact stitch spacing for ground plane of antennas and at the same time reducing the cost of production of the stitched antennas. Full control of the stitch pattern is achieved. A higher conductive path was achieved on the mesh designs. Current follows along with the stitched patch of ground plane. This stitched ground was applied to microstrip patch antennas. The patch antennas were designed at $5 \mathrm{GHz}$ with the same dimensions and with differing format ground planes of the same size. A solid patch with solid ground plane was used for comparison with the stitched ground planes. Closer stitched configuration was achieved which gives resonant frequency at $5 \mathrm{GHz}$. A fabric patch design with stitched ground shows comparable performance to conventional copper patch antenna of the same design.

\section{Conflicts of Interest}

The author declares no conflicts of interest regarding the publication of this paper. 


\section{References}

[1] Zhang, S., Whittow, W., Seager, R., Chauraya, A. and Vardaxoglou, J.C. (2017) Non-Uniform Mesh for Embroidered Microstrip Antennas. IET Microwaves, Antennas \& Propagation, 11, 1086-1091. https://doi.org/10.1049/iet-map.2016.0901

[2] Zhang, S., Chauraya, A. and Whittow, W.G. (2014) Embroidered Wearable Antennas Using Conductive Threads with Different Stitch Spacings. 2012 Loughborough Antennas \& Propagation Conference (LAPC), Loughborough, UK, 12-13 November 2012, 1-4. https://doi.org/10.1109/LAPC.2012.6403059

[3] Chauraya, A., Whittow, W.G., Vardaxoglou, J.C., Yi, L., Torah, R., Yang, K., Beeby, S. and Tudor, J. (2013) Inkjet Printed Dipole Antennas on Textiles for Wearable Communications. IET Microwaves, Antennas \& Propagation, 7, 760-767. https://doi.org/10.1049/iet-map.2013.0076

[4] Gil, I., Fernández-García, R. and Tornero, J.A. (2019) Embroidery Manufacturing Techniques for Textile Dipole Antenna Applied to Wireless Body Area Network. Textile Research Journal, 89, 1573-1581. https://doi.org/10.1177/0040517518770682

[5] Chedid, M., Belov, I. and Leisner, P. (2007) Experimental Analysis and Modelling of Textile Transmission Line for Wearable Applications. International Journal of Clothing Science and Technology, 19, 59-71. https://doi.org/10.1108/09556220710717053

[6] Ferreira, D., Pires, P., Rodrigues, R. and Caldeirinha, R.F. (2017) Wearable Textile Antennas: Examining the Effect of Bending on Their Performance. IEEE Antennas and Propagation Magazine, 59, 54-59. https://doi.org/10.1109/MAP.2017.2686093

[7] Vallozzi, L., Vandendriessche,W., Rogier,H., Hertleer, C. and Scarpello, M.L. (2010) Wearable Textile GPS Antenna for Integration in Protective Garments. Proceedings of the Fourth European Conference on Antennas and Propagation, Barcelona, Spain, 12-16 April 2010, 1-4.

[8] Corchia, L., Monti, G. and Tarricone, L. (2018) Durability of Wearable Antennas Based on Nonwoven Conductive Fabrics: Experimental Study on Resistance to Washing and Ironing. International Journal of Antennas and Propagation, 2018, Article ID: 2340293. https://doi.org/10.1155/2018/2340293

[9] Kiourti, A. and Volakis, J.L. (2015) Colorful Textile Antennas Integrated into Embroidered Logos. Journal of Sensor and Actuator Networks, 4, 371-377. https://doi.org/10.3390/jsan4040371

[10] Clasen, G. and Langley, R. (2004) Meshed Patch Antennas. IEEE Transactions on Antennas and Propagation, 52, 1412-1416. https://doi.org/10.1109/TAP.2004.830251

[11] Turpin, T.W. and Baktur, R. (2009) Meshed Patch Antennas Integrated on Solar Cells. IEEE Antennas and Wireless Propagation Letters, 8, 693-696.

https://doi.org/10.1109/LAWP.2009.2025522

[12] Krupka, J., Geyer, R.G., Baker-Jarvis, J. and Ceremuga, J. (1996) Measure Ments of the Complex Permittivity of Microwave Circuit Board Substrates Using Split Dielectric Resonator and Reentrant Cavity Techniques. Seventh International Conference on Dielectric Materials, Measurements and Applications, Bath, UK, 23-26 September 1996, 21-24. https://doi.org/10.1049/cp:19960982

[13] Balanis, C.A. (2016) Antenna Theory Analysis and Design. John Willey and Son's Inc, Hoboken.

[14] Pozar, D.M. (1992) Microstrip Antennas. Proceedings of the IEEE, 80, 79-91. https://doi.org/10.1109/5.119568 
[15] Wiri, A.T. (2019) Automated Design, Optimization and Simulation of Stitched Antennas for Textile Devices. Ph.D. Dissertation, Loughborough University, Loughborough, UK.

[16] Wu, F.Y. (2009) Theory of Resistor Networks: The Two-Point Resistance. Exactly Solved Model. Journal of Physics A: Mathematical and General, 37, Article No. 26. http://stacks.iop.org/ja/37/6653 https://doi.org/10.1088/0305-4470/37/26/004

[17] Venezian, G. (1994) On the Resistance between Two Points on a Grid. American Journal of Physics, 62, 1000. https://doi.org/10.1119/1.17696 